\title{
Erratum to: Bimatoprost for Eyelash Growth in Japanese Subjects: Two Multicenter Controlled Studies
}

\author{
K. Harii $\cdot$ S. Arase $\cdot$ R. Tsuboi $\cdot$ E. Weng $\cdot$ \\ S. Daniels $\cdot A$. VanDenburgh
}

Published online: 19 August 2014

(C) Springer Science+Business Media New York and International Society of Aesthetic Plastic Surgery 2014

\section{Erratum to: Aesth Plast Surg (2014) 38:451-460}

DOI 10.1007/s00266-014-0293-7

In the original publication of this article, Fig. $4 \mathrm{~b}$ is a duplicate of Fig. 4a. The correct Fig. 4b appears here.

The online version of the original article can be found under doi:10.1007/s00266-014-0293-7.

\section{K. Harii}

Department of Plastic Surgery, Kyorin University, School of Medicine, Tokyo, Japan

S. Arase

Health Insurance Naruto Hospital, Tokushima, Japan

R. Tsuboi

Department of Dermatology, Tokyo Medical University, Tokyo, Japan

E. Weng Dermatology Clinical Research and Development, Allergan, Inc., Irvine, CA, USA

S. Daniels

Global Health Outcomes, Strategy and Research, Allergan, Inc., Irvine, CA, USA

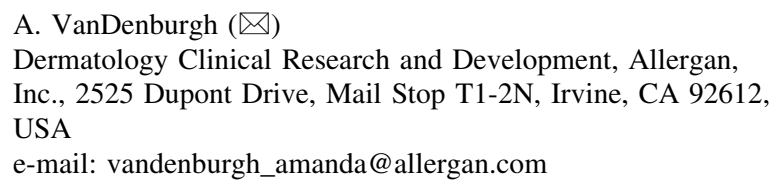


Fig. 4 Examples of subjects who responded to bimatoprost treatment with an increase in a upper eyelash length,

b thickness, and c darkness, including baseline and month 4 , as well as a change from baseline values (measurements are rounded to the nearest whole number). The individual changes in these subjects were comparable with the mean changes observed in the bimatoprost group in a study 1 and b study 2. IU intensity units
B

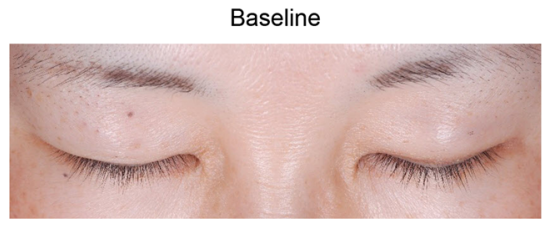

$6.6 \mathrm{~mm}$

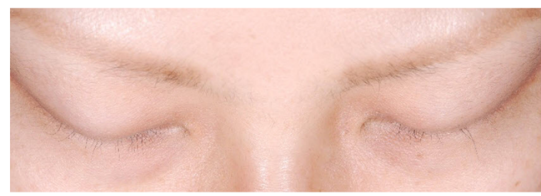

$0.1 \mathrm{~mm}^{2}$

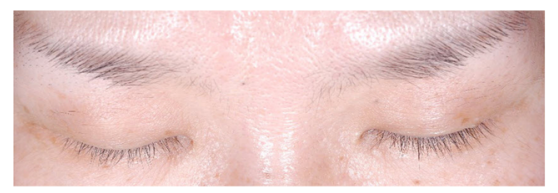

$161.0 \mathrm{IU}$
Month 4

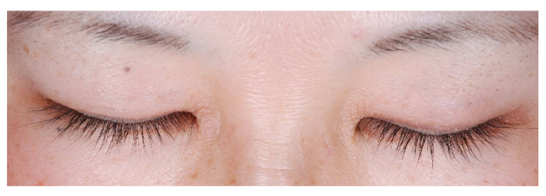

$9.4 \mathrm{~mm}$ (change: $2.8 \mathrm{~mm}$ )

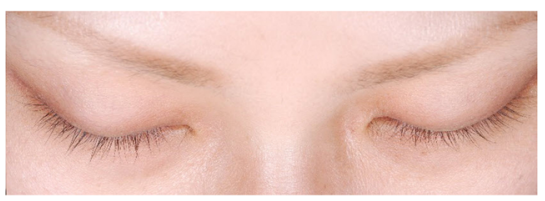

$0.7 \mathrm{~mm}^{2}$ (change: $0.6 \mathrm{~mm}^{2}$ )

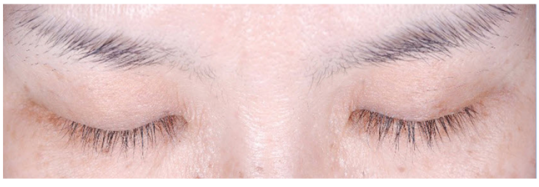

141.6 IU (change: -19.4 IU) 